\title{
Bioethics in Nigeria: Knowledge and perception during a capacity-building workshop for Biomedical researchers.
}

Olabanji Ahmed Surakat ( $\nabla$ olabanji.surakat@uniosun.edu.ng )

Osun State University

\section{Babafemi Siji Ajisebiola}

Osun State University

Hammed Mogaji

Federal University Oye-Ekiti

Sandra Onakhinor

Osun State University

Lateef Oladimeji Busari

Osun State University

Oyinkansola Fadiji

Federal University of Agriculture

Oluwadamilare Dauda

Osun State University

Mohammed Rufai

Osun State University

Monsuru Adeleke

Osun State University

Sammy Olufemi Sam-Wobo

Federal University of Agriculture

\section{Research Article}

Keywords: Bioethics, Biomedical researchers, Knowledge and Perception

Posted Date: August 16th, 2021

DOI: https://doi.org/10.21203/rs.3.rs-798468/v1

License: @ (i) This work is licensed under a Creative Commons Attribution 4.0 International License. Read Full License 


\section{Abstract}

Background: The need to assess the gaps in knowledge and perception on bioethics among biomedical researchers has become necessary considering the increasing numbers of researchers and research outputs in sub-Saharan Africa. This study, therefore, investigated the knowledge and perceptions of biomedical researchers in Osun State, southwest Nigeria.

Methods: Pre-tested semi-structured questionnaires were administered to consenting biomedical researchers during a capacity workshop conducted in November 2020. The questionnaire collected data on the attendee's demography, knowledge, awareness and perception on bioethics and ethical approvals for research. Quantitative data were analysed using descriptive statistics in SPSS. 20.0 software and expressed as frequencies and percentages. Associations between professional status of participants were performed using chi-square statistics, and confidence interval was set as $95 \%$. However, qualitative data were obtained using open-ended questionnaires and analysed thematically.

Results: A total of 153 biomedical researchers across 33 academic and research institutions, comprising $58 \%$ males, and $42 \%$ females participated in this study. The age of the participants ranged from 20 to 60 years. Majority of the participants $(60.8 \%)$ hold academic positions and about one-third of the population were graduate students (30.1\%). Awareness on bioethics was high (91.5\%), and more common in schools (61.4\%), with majority of the participants $(77.1 \%)$ describing it as a field that addresses the social and legal issues arising from medicine and life sciences $(p<0.05)$. However, participants' perception of the principles of ethics was poor, with about $16 \%$ of participants considering none or only part of the principles. Also, about $10 \%$ felt they could still obtain ethical permits while research is ongoing or completed, while only $13.7 \%$ affirms that all biomedical related researches require ethical approval. There were significant differences in the proportions across the professional status of participants $(p<0.05)$.

Conclusion: The study has revealed poor perception among participants and suggests the prioritization of bioethics capacity enhancement workshops to improve knowledge and perceptions of biomedical researchers. In addition, more detailed studies across institutions in Nigeria should be carried out to assess, monitor and reinforce knowledge gained by biomedical researchers.

\section{Introduction}

The word "Bioethics" was first coined by Fritz Jahr in 1927, and has gained considerable attention till date as it employs ethical theories derived from the considerations of philosophy, law and politics to address some of the problems encountered in the field of biology, including medicine (Gillon, 1998). Biomedical research or experiments targeted at advancing science and promoting societal development are expected to be performed according to established rules and standards known as Ethics, which basically involves doing what is right and acceptable within a specified context. The 1947 Nuremberg Code and 1964 Helsinki Declaration remained the point of reference for most ethical norms, which are implemented by ethical committees (EC) across various countries. EC are saddled with the responsibility of ensuring biomedical research or otherwise are guided and performed by researchers according to set standards (WHO, 2002). 
National laws and regulations in several countries require mandatory review and approval of biomedical research before commencement of research studies (Andanda et al., 2011; Langlois, 2011). Unfortunately, the WHO Regional Committee for Africa in 2001 reported that some studies in the region were not undergoing any form of ethics review (Kirigia et al., 2005). In addition, a common misconception about ethics, is that ethical consideration are targeted at ensuring research participants are protected from exploitation and other forms of harm (Emanuel et al., 2000). However, beyond the concept of protection, biomedical research or experiments should be guided by other principles of autonomy, non-maleficence, beneficence, and justice (Rai et al., 2015). Refusals to submit research protocols for ethics review during biomedical research or experiments does not only vitiate the validity of the research but also dents the integrity of the researcher. In addition, biomedical research that poses risk, un-beneficial or with doubt to participants, have potentials to contribute to cohort fallout, loss of public trust, and reduced community participation and engagement (Harkness et al., 2001; Merslin and Garba, 2011; Ursin, 2010).

It has therefore become imperative to consider investments that will encourage submissions of research protocols to EC for approvals, and ensure high ethical standard are maintained during investigations. However, the exponential growth in the numbers of biomedical researchers and the consequential increase in research activities in sub-Saharan Africa like most developing countries have not been complemented with capacity enhancement workshops on bioethics. (Andanda et al., 2011: Gordijn B, 2014; Blessing and Wassenaar, 2015). In South-west Nigeria, there are emerging evidence corroborating the lack of knowledge and practices of ethics among biomedical researchers (Ogunrin et al., 2016). This gap in knowledge suggest the need to invest in the training and re-training of biomedical researchers, either through the incorporation of a revised ethics module in curriculum of postgraduate students, or through more flexible medium such as seminars or short courses approach for other career researchers.

To this end, a one-day workshop on bioethics for biomedical researchers in Nigeria was organized by Osun State University in partnership with the Global Health Network, University of Oxford to stimulate and promote the needs for healthy research culture while ensuring ethical standards and procedures are met. This study then investigated the knowledge and perceptions of participants at the workshop prior to the time the workshop facilitators began their presentations with the aim of profiling gaps in knowledge, perceptions and practices about bioethics.

\section{Methods}

\section{Study Area}

This study was conducted in Osun State. The State is one of the six states located in the southwestern part of Nigeria and is divided into 30 administrative regions known as the Local Government Areas (LGAs). The state has the second-highest number of tertiary institutions universities in Nigeria with one Federal University, one State University and eight privately run universities.

\section{Planning and preparatory activities}

This study was conducted during the one-day workshop on "Ethics in Biomedical Research and global best practices in the context of Preventive Chemotherapy Neglected Tropical Diseases (PC-NTDs) Elimination 
strategy in Nigeria" organized by the Department of Zoology, Osun State University, November 2020. The workshop was advertised via the web (email, Twitter, WhatsApp and Facebook) and participants were invited to register before the workshop. However, only those who were in the field of biology or biomedical sciences were invited to participate in the workshop.

\section{Questionnaire administration}

The study was cross-sectional in design and involved the administration of already pretested semi-structured questionnaires to collect both quantitative and qualitative data from consenting participants. Participants were approached at the registration desk of the event and invited to participate in the study. Information such as participants' demographic data, and their knowledge and perception about bioethics were assessed using the questionnaires. To prevent event-induced responses and biases, participants completed the questionnaires before proceeding with registration or gaining access to the event hall.

\section{Data analysis}

Data obtained were entered into Microsoft Excel 2019 software. Quantitative data were analysed using descriptive statistics in SPSS. 20.0 and expressed as frequencies and percentages. Cross-tabulations and Chisquare analysis were performed to investigate associations. The Confidence interval was set at $95 \%$. However, qualitative data were obtained using open-ended questionnaires, manually coded based on emerging themes and summarized.

\section{Results}

\section{Demographic characteristics of study participants}

A total of 153 participants consented to the study procedures and participated in the study. By gender, majority of the participants were males $89(58 \%)$, and $64(42 \%)$ were females. The age of the participants ranges from 20 to 60 years, and those aged 36 and above were in abundance, 72(47.1\%), followed by those between 26 and 35 years with $58(37.1 \%)$ and the least number of participants were those below the age of 25 years with $23(15.0 \%)$. By occupation, majority of the participants hold academic positions in tertiary institutions (60.8\%), followed by students representing one-third of the population $(30.1 \%)$ and the least were clinicians $(1.3 \%)$ (Table 1).

The participants who were drawn from thirty-three (33) academic institutions across Nigeria responded to the questionnaire. The research scope of the participants ranged from basic science to molecular biology.

Table 1: Demographic information of study participants 


\begin{tabular}{|lll|}
\hline & Number of respondents & Percentage \\
\hline Gender & & \\
\hline Female & 64 & 41.8 \\
\hline Male & 89 & 58.2 \\
\hline Total & 153 & 100.0 \\
\hline & & \\
\hline Age (in years) & & \\
\hline $18-25$ & 23 & 15.0 \\
\hline $26-35$ & 58 & 37.9 \\
\hline$\geq 36$ & 72 & 47.1 \\
\hline Total & 153 & 100.0 \\
\hline & & \\
\hline Occupation & & 60.8 \\
\hline Academia/Lecturer & 93 & 1.3 \\
\hline Clinician & 2 & 7.8 \\
\hline Government worker & 12 & 30.1 \\
\hline Students & 46 & 100.0 \\
\hline Total & 153 & \\
\hline
\end{tabular}

\section{Participants' awareness and knowledge about bioethics}

Majority of the participants, $140(91.5 \%)$ have heard of bioethics. The clinicians have heard of bioethics prior the workshop 2(100\%), and 44(96\%) of the students who participated were aware of bioethics, followed by participants, $86(93 \%)$ who hold academic positions in tertiary institutions. There were significant differences in the proportions of participants who are aware of bioethics prior to the workshop across the occupational status ( $p<0.05)$. Majority of the participants $94(61.4 \%)$ affirmed they learnt about bioethics while in schools, this was more common for the students $34(74 \%)$, followed by civil servants $7(58.3 \%)$ and those in academics 53(57\%). An appreciable number of participants 19(12.4\%) also affirmed that they learnt about bioethics on institutional review boards. The civil servants affirmed this in high proportions $4(33.3 \%)$ compared to those in academia $15(16.1 \%)$. The internet and advert of the event also contributed to awareness creation for $17(11.1 \%)$ and $10(6.5 \%)$ of the participants respectively. However, only $2.0 \%$ of the participants affirmed they learnt about bioethics on a radio program. There were significant differences in the proportions of where participants learnt about bioethics across the occupational status $(p<0.05)$. Majority of the participants $118(77.1 \%)$ ascribed the description of bioethics to social and legal issues arising from medicine and the life sciences, this was 
followed by $25(16.3 \%)$ who described it as human understanding of well-being and about $10(6.5 \%)$ felt it is a critic reflection about ethical conflicts. There were no significant differences in the proportions of participants across the descriptions of bioethics and their occupational status ( $p>0.05)$ (Table 2$)$.

Table 2: Participants' awareness and knowledge about bioethics 
Occupation of study participants

$\mathrm{x}^{2}, \mathrm{df}$

$\mathrm{p}$-value
Have you heard about

bioethics before this event?

Yes

$2(100) \quad 86(92.5) \quad 8(66.7) \quad 44(95.7)$

$0(0)$

2(1.3)

No

Total

Civil
servant

Student/

Total

unemployed

\section{Where did you first learn about} bioethics?

Institutional review boards

$0(0)$

15(16.1)

$4(33.3)$

$0(0)$

19(12.4)

76.889,

18

10.828,

3 ,

0.013

0.000

Internet

National ethics board

Schools

Radio program

Hospital/clinics

Event advert

Total
$0(0)$

O(0)

$0(0)$

$0(0)$

2(100)

$0(0)$

2(1.3)
$10(10.8)$

0(0)

53(57)

3(3.2)

4(4.3)

8(8.6)

93(60.8)

1(8.3) 6(13.0)

$0(0)$

7(58.3)

$0(0)$

0(0)

0(0)

$12(7.8)$
4(8.7)

34(73.9)

O(0)

$0(0)$

2(4.4)

46(30.1)
13(8.5)

153(100)

Which of the following best

describes bioethics

Critic reflection about ethical conflicts

$\begin{array}{llll}0 & 3(3.2) & 1(8.3) & 6(13.0)\end{array}$

$10(6.5)$

9.526 ,

9 ,

0.390

Human understanding of well- $\quad 0 \quad 16(17.2) \quad 4(33.3) \quad 5(10.9) \quad 25(16.3)$
being

Social and Legal issues arising $\quad 2(100) \quad 74(79.6) \quad 7(58.3) \quad 35(76.1) \quad 118(77.1)$

from medicine and the life

sciences

Total

2(1.3)

$93(60.8)$

12(7.8) 46(30.1)

153(100) 
Majority of the participants $140(91.5 \%)$ perceived it is necessary to obtain ethical approvals before the study, with the highest proportion of responses recorded among clinicians $2(100 \%)$, followed by those holding academic positions $88(94.6 \%)$, students $41(89.1 \%)$ and civil servants $9(75 \%)$. About $25 \%$ of the participants that were civil servants felt they could still obtain ethical permits during the study process, and some students $2(4.4 \%)$ and academic staff $2(2.2 \%)$ felt they can obtain a permit after the study. There were no significant differences in the proportions of participants across the time when approvals should be sought and their occupational status $(p>0.05)$ (Table 3$)$.

Furthermore, the perception of participants varied regarding the bioethics principles to be considered while planning for research. Majority of the participant 128(83.6\%) affirmed that issues surrounding the need, respect, risk and benefits of the research should be considered. Clinicians and civil servants affirmed totally to this, with $2(100 \%)$ and $12(100 \%)$ respectively. However, some academic staff, $12(12.9 \%)$ and students, $6(13 \%)$ felt on the risk and benefits of the study to the participants should be considered. Also, $2(2.2 \%)$ of the academic staff felt none of these principles should be considered. There were significant differences in the proportions of participants across their perceptions about bioethics principles and their occupational status ( $p$ $<0.05$ ) (Table 3).

The perceptions of participants varied around the type of research that requires ethical approvals. Majority of the participants felt only clinical research $47(30.7 \%)$ and Animal experimental research $46(30.1 \%)$ should apply for ethical approvals. This was followed by research involving collection of human bio-samples, $37(24.3 \%)$ and the least was behavioural studies with $2(1.3 \%)$. Only $21(13.7 \%)$ affirmed that all these types of studies needs ethical approval, with responses from those holding academic positions $19(12.4 \%)$, civil servants $1(8.3 \%)$ and students $1(2.2 \%)$. There were no significant differences in the proportions of participants across their perceptions about the type of study that requires ethical permits and their occupational status $(p<0.05)$. Majority of the respondents, $144(94.1 \%)$ agreed that a manuscript can be rejected if the underlying study has no ethical approval. However, some academic staff $7(7.5 \%)$ and students $9(5.9 \%)$ felt such manuscripts can still be accepted. There were no significant differences in the proportions of participants across their occupational status $(p<0.05)($ Table 3$)$.

\section{Table 3: Participants' perception about bioethics and ethical approvals}


Occupation of study participants

$\begin{array}{lllll}\text { Clinician Academia } & \begin{array}{l}\text { Civil } \\ \text { servant }\end{array} & \begin{array}{l}\text { Student/ } \\ \text { unemployed }\end{array} & \text { Total } & \begin{array}{l}\mathrm{X}^{2}, \mathrm{df} \\ \mathrm{p} \text {-value }\end{array} \\ & & \end{array}$

When do you think it is necessary to obtain ethical clearance for your study?

$\begin{array}{lllllll}\text { Before } & 2(100) & 88(94.6) & 9(75) & 41(89.1) & 140(91.5) & \begin{array}{l}10.193, \\ 6, \\ 0.117\end{array} \\ \text { After } & 0(0) & 2(2.2) & 0(0) & 2(4.4) & 4(2.6) & \\ \text { During } & 0(0) & 3(3.2) & 3(25) & 3(6.5) & 9(5.9) & \\ \text { Total } & 2(1.3) & 93(60.8) & 12(7.8) & 46(30.1) & 153(100)\end{array}$

\section{Which of the following bioethics principle should be} considered while planning for research?

\begin{tabular}{llllll} 
Justification to participants & $0(0)$ & $3(3.2)$ & $0(0)$ & $0(0)$ & $3(2.0)$ \\
$\begin{array}{l}\text { Respect for participants } \\
\begin{array}{l}\text { Risk and benefits to the } \\
\text { participants }\end{array}\end{array}$ & $0(0)$ & $2(2.2)$ & $0(0)$ & $0(0)$ & $2(1.3)$ \\
$\begin{array}{l}\text { All of the above } \\
\text { None of the above }\end{array}$ & $2(100)$ & $74(79.5)$ & $12(100)$ & $40(87)$ & $128(83.6)$ \\
\hline Total & $0(0)$ & $2(2.2)$ & $0(0)$ & $0(0)$ & $2(1.3)$ \\
\hline
\end{tabular}

Which type of research do you need ethical clearance?

$\begin{array}{llllll}\text { Animal experimental research } 2(100) \quad 26(27.9) & 6(50) & 12(26.1) & 46(30.1) & 25.115, \\ & & & 0.14\end{array}$

\begin{tabular}{|c|c|c|c|c|c|c|}
\hline Behavioral studies & $0(0)$ & $0(0)$ & $1(8.3)$ & $1(2.2)$ & $2(1.3)$ & \\
\hline Clinical research & $0(0)$ & $24(25.8)$ & $3(25)$ & $20(43.4)$ & $47(30.7)$ & \\
\hline Human bio-samples & $0(0)$ & $24(25.8)$ & $1(8.3)$ & $12(26.1)$ & $37(24.2)$ & \\
\hline All of the above & $0(0)$ & 19(12.4) & $1(8.3)$ & $1(2.2)$ & 21(13.7) & \\
\hline Total & $2(1.3)$ & $93(60.8)$ & 12(7.8) & $46(30.1)$ & $153(100)$ & \\
\hline \multicolumn{7}{|c|}{$\begin{array}{l}\text { Do you think that a manuscript can be rejected due to a } \\
\text { lack of proper ethical review? }\end{array}$} \\
\hline Yes & $2(100)$ & $86(92.5)$ & $12(100)$ & $44(95.7)$ & $144(94.1)$ & $\begin{array}{l}1.525, \\
3, \\
0.677\end{array}$ \\
\hline No & $0(0)$ & $7(7.5)$ & $0(0)$ & $2(4.3)$ & $9(5.9)$ & \\
\hline
\end{tabular}




\section{Participants' perception about capacity building in bioethics}

Although majority of the participants $89(58.2 \%)$ have had a need for bioethics certification before, about half, $64(41.8 \%)$ of the participants have not had any need for bioethics certification before the event, with an appreciable number from civil servants $8(66.7 \%)$, students $29(63 \%)$ and those holding academic positions $27(29 \%)$. There were significant differences in the proportion of participants across their need for a bioethics certification and their occupational status $(p<0.05)$. Majority of the participants, $147(96.1 \%)$ felt there should be regular mid-career training on bioethics for biomedical researchers, and $151(98.7 \%)$ of them were willing to participate in future workshops (Table 4).

\begin{tabular}{|c|c|c|c|c|c|c|}
\hline \multicolumn{7}{|c|}{ Occupation of study participants } \\
\hline & Clinician & Academia & $\begin{array}{l}\text { Civil } \\
\text { servant }\end{array}$ & $\begin{array}{l}\text { Student/ } \\
\text { unemployed }\end{array}$ & Total & $\begin{array}{l}x^{2}, d f, \\
p \text {-value }\end{array}$ \\
\hline \multicolumn{7}{|c|}{ Have you had a need for bioethics certification before? } \\
\hline Yes & $2(100)$ & $66(71)$ & $4(33.3)$ & $17(37)$ & $89(58.2)$ & $\begin{array}{l}\text { 19.248, } \\
3 . \\
0.000\end{array}$ \\
\hline No & $0(0)$ & $27(29)$ & $8(66.7)$ & $29(63)$ & $64(41.8)$ & \\
\hline Total & $2(1.3)$ & $93(60.8)$ & 12(7.8) & $46(30.1)$ & 153(100) & \\
\hline \multicolumn{7}{|c|}{$\begin{array}{l}\text { Do you think that there should be a regular mid-career } \\
\text { training on bioethics? }\end{array}$} \\
\hline Yes & $0(0)$ & 92(98.9) & 12(100) & $43(93.5)$ & 147(96.1) & $\begin{array}{l}52.315, \\
3, \\
0.000\end{array}$ \\
\hline No & $2(100)$ & $1(1.1)$ & $0(0)$ & $3(6.5)$ & $6(3.9)$ & \\
\hline Total & $2(1.3)$ & $93(60.8)$ & $12(7.8)$ & $46(30.1)$ & $153(100)$ & \\
\hline \multicolumn{7}{|c|}{$\begin{array}{l}\text { Will you wish to participate in future training on } \\
\text { bioethics? }\end{array}$} \\
\hline Yes & $2(100)$ & $91(97.9)$ & 12(100) & $46(100)$ & 151(98.7) & $\begin{array}{l}1.307 \\
3, \\
0.727\end{array}$ \\
\hline No & $0(0)$ & $2(2.1)$ & $0(0)$ & $0(0)$ & $2(1.3)$ & \\
\hline Total & $2(1.3)$ & $93(60.8)$ & $12(7.8)$ & $46(30.1)$ & $153(100)$ & \\
\hline
\end{tabular}




\section{Table 4: Participants' perception about capacity building in bioethics}

\section{Discussion}

This study investigated the knowledge and perceptions of biomedical researchers on bioethics, with the aim of profiling gaps in knowledge, perceptions and practices. Our finding contributes to the emerging evidences on poor knowledge and practices among biomedical researchers in the south-western part of Nigeria (Ogunrin et al., 2016). The awareness about bioethics among the study participants was high, and expected, since bioethics has gained popularity in academic environments where students and biomedical researchers are required to submit protocols for ethics approval before field or laboratory experiment. In addition, the popularity of bioethics in field of medicine is higher since the interactions with human subjects are more pronounced when compared to other biomedical disciplines. Our findings therefore show an increased awareness among the study participants on social and legal issues upon which the principles of bioethics are built. However, the assumption that awareness would translate to improved knowledge and practices is faulty, since the training process for bioethics among biomedical researchers is usually passive (Ogunrin et al., 2013). This can be attributed to the fact that there is paucity of postgraduate programs focusing on bioethics in Nigeria. As such, awareness creation and knowledge transfer occur subconsciously via interaction with advisors, institutional review boards, workshops or in some instances on radio program as expressed by the participants of this study. The importance of open symposiums, workshops and radio program as important advocacy medium have been previously discussed (Advocacy Partnership, 2012; Mogaji et al., 2021), and should also be considered in promoting awareness, improved knowledge and practices among biomedical researchers. However, these modes of knowledge transfer cannot provide exhaustive information on the background, principles of bioethics and requirements for ethical approval within the short period of time stipulated for delivery (Xu et al., 2020).

Furthermore, about $10 \%$ of the study participants believe that ethical approval for research protocols can be obtained while the experiment has started, and some affirmed that approvals can be obtained when the experiment has been completed. An appreciable number of participants also felt, only the risk and benefits of a research should be taken seriously, while others felt none of the principles should be considered. This finding corroborate with the reports of Ogunin et al., (2016) and Ateudjieu et al., (2019), that only few researchers are aware of ethical principles guiding the conduct of a research. These observations reflect a gap in knowledge and in-depth understanding of bioethics and re-iterate the need to consider a more robust medium for training and/or re-training of biomedical researchers. We therefore propose that bioethics module be incorporated in the curriculum of graduate students, and other flexible medium such as short courses or seminars can be used to complement or reinforce knowledge or skills acquired.

There were also discrepancies in the participant's view about the type of research that requires ethical approvals, with majority of the participants placing more importance on clinical and animal experimental studies, while neglecting behavioral studies. This perception might be influenced by the erroneous believe that ethical approvals are only associated with experimental studies, unlike research involving the use of questionnaires or interviews (Bowling, 2005). Researchers may therefore evade or refuse to seek ethical permissions prior to the commencement of their study, and may do otherwise after or during the research to satisfy manuscript submission requirements as clearly expressed by some of the participants. It is therefore 
imperative that the proposed bioethics module should offer biomedical researchers opportunity to learn the need for ethical approvals and the range of research study that require such approvals in addition to the basic principles of bioethics. Such trainings should lead to certifications that should accompany protocols that are submitted for ethical approvals (Yakubu and Adebamowo, 2012)

\section{Conclusion}

This study has revealed the poor understanding and practice of research ethics among biomedical researchers. Hence, there is a need for continuing and expanded support from the international bioethics' community such as the Global Health Network that sponsored this workshop to develop capacity for training of researchers in developing countries. The initiatives to provide training grants for bioethics programmes within and outside Africa by the National Institute of Health of the United States and the support of other institutions and bodies like the Wellcome Trust, African Malaria Network Trust (AMANET) and European Forum for Good Clinical Practice (EFGCP) among others, to the course of bioethics in Africa are noteworthy (Ogundiran, 2004). The prioritization of bioethics workshop and training across universities in Nigeria is highly recommended and more detailed studies across institutions in Nigeria should be done in order to assess, monitor and improve the knowledge of health researchers on research ethics.

\section{Declarations}

\section{Ethics approval and consent to participate}

This study received ethical approval from the Ethics Review Committees of Faculty of Basic and Applied Sciences, Osun State University. Those who agreed to participate were given informed consent forms to complete after the purpose of the study has been explained to them. Formal consent was obtained through a duly completed consent form with the name and signature of the attendee. All procedures performed in studies

involving human participants were in accordance with the ethical standards of the institutional and/or national research committee and with the 1964 Helsinki declaration and its later amendments or comparable ethical standards.

\section{Consent for publication}

No personally identifying information was included in this research.

\section{Availability of data and materials}

The datasets generated and analyzed during this study may be requested from the authors.

\section{Competing interests}

The authors declare that they have no conflict of interest related to this work.

\section{Funding}

Funding was received from The Global Health Network (TGHN) University of Oxford to conduct the Bioethics workshop. The funding was as a result of a video competition won by the lead author in a video contest 
advertised by the Global Health Network, 2019. The research study conducted during the workshop did not receive any funding. The funders of the workshop had no role in data collection, analysis or reporting.

\section{Authors' contributions}

OAS, HM, MAA, and SOS designed of the survey, interpretation of the data and preparation of the manuscript; BSA and SOO, LOB, OGD contributed to data collection. OF, MR, OAS and HM contributed to the analysis, of the data. All authors have read and approved the final version of the manuscript before submission. All authors have agreed both to be personally accountable for their own contributions and to ensure that questions related to the accuracy or integrity of any part of the work, were appropriately investigated, resolved, and the resolution documented in the literature.

\section{Acknowledgement}

The authors wish to thank the Global Health Network, University of Oxford, United Kingdom for the workshop funding support (REF: C637) which was as a result of the video competition won by the lead author.

\section{Disclaimer}

The views expressed here are those of the authors and are not necessarily a reflection of the knowledge of Bioethics in Nigeria.

\section{Abbreviations}

EC: Ethical Committee

WHO: World Health Organization

The Global Health Network: TGHN

Local Government Areas: LGAs

Preventive Chemotherapy-Neglected Tropical Diseases PC-NTDs

African Malaria Network Trust: AMANET

European Forum for Good Clinical Practice: EFGCP

\section{References}

1. Gillon, R. 1998. Bioethics, Overview, Editor(s): Ruth Chadwick, Encyclopedia of Applied Ethics (Second Edition), Academic Press, Pages 267-277, ISBN 9780123739322, https://doi.org/10.1016/B978-0-12373932-2.00385-9.

2. World Health Organization. 2002. Strategic Initiative for Developing Capacity in Ethical Review (SIDCER): terms of reference and strategic plan. Geneva: 
3. Andanda P, Awah P, Ndebele P, Onigbogi O, Udatinya D, et al. (2011). The ethical and legal regulation of HIV-vaccine research in Africa: lessons from Cameroon, Malawi, Nigeria, Rwanda and Zambia. African J AIDS Res 10: 451-63.

4. Langlois, A. (2011). The Global Governance of Bioethics: Negotiating UNESCO's Universal Declaration on Bioethics and Human Rights (2005). London, England: Routledge

5. Kirigia, J. M., Wambebe, C., \& Baba-Moussa, A. (2005). Status of national research bioethics committees in the WHO African region. BMC Medical Ethics, 6, 10. doi:10.1186/1472-6939-6-10.

6. Emanuel EJ, Wendler D, Grady C (2000) What Makes Clinical Research Ethical? JAMA 283: 2701-2711.

7. Rai R, Prashanth GM, Imranulla M, Allama Prabhu CR, Vivek HP.A Ethics in Biomedical Research. Int J Oral Health Med Res (2015); 2(2):102-110.

8. Harkness J, Lederer SE, Wikler D (2001) Laying ethical foundations for clinical research. Bull World Health Organ 79: 365-372.

9. Meslin EM, Garba I (2011) Biobanking and public health: Is a human rights approach the tie that binds? Hum Genet 130: 451-463.

10. Ursin LO (2010) Privacy and property in the biobank context. HEC Forum 22: 211-224.

11. Gordijn B (2014) Handbook of Global Bioethics. Springer publications, pp. 649-670.

12. Blessing Silaigwana, B and Wassenaar, D (2015). Biomedical Research Ethics Committees in Sub-Saharan Africa. Journal of Empirical Research on Human Research Ethics. 1-16

13. Ogunrin OF, Ogunrin OA, Murray BJ (2016) Knowledge and Practice of Research Ethics among Biomedical Researchers in Southern Nigerian Tertiary Institutions. J Clin Res Bioeth 7: 1000274. doi:10.4172/21559627.1000274

14. Ogunrin, O.A., Ogundiran, T.O and Adebamowo, C. 2013. Development and pilot testing of an online module for ethics education based on the Nigerian National Code for Health Research Ethics. BMC Med Ethics 14 (1): 1-17

15. Advocacy partnership. TB/MDR-TB Advocacy Tool Kit. [Online]. 2012. Available at http://www.stoptb.org/assets/documents/global/awards/cfcs/tb_mdr\%20advocacy\%20tool\%20kit.pdf.

16. Mogaji HO, Odoh IM, lyeh Cl, Adeniran AA, Oyedeji SI, et al. (2021) Attendee's awareness about preventive chemotherapy neglected tropical diseases (PC-NTD) control during the first world neglected tropical diseases day in Ekiti State, Nigeria. PLOS Neglected Tropical Diseases 15(3): e0009315. https://doi.org/10.1371/journal.pntd.0009315

17. Xu, A., Baysari M.T., Stocker, S.L., Leow, L.J., Day, R.O., and Carland J.E. 2020. Researchers' view on, and experiences with, the requirement to obtain informed consent in research involving human participants: a qualitative study. BMC Med Ethics 21 (93): 1-11

18. Ateudjieu, J., Hurst, S., Yakum, M.N. et al. Biomedical research ethics in Cameroon: a survey to assess training needs of medical residents and students. BMC Med Educ 19, 5 (2019). https://doi.org/10.1186/s12909-018-1431-8.

19. Bowling A. 2005. Mode of questionnaire administration can have serious effects on data analysis. Journal of Public Health 27 (3): 281-291 
20. Yakubu, A., \& Adebamowo, C. A. (2012). Implementing National System of Health Research Ethics Regulations: The Nigerian Experience. BEOnline : journal of the West African bioethics training program, 1(1), 4-15.

21. Ogundiran, T.O. Enhancing the African bioethics initiative. BMC Med Educ 4, 21 (2004). https://doi.org/10.1186/1472-6920-4-21 